\title{
LA DICOTOMÍA PÚBLICO/PRIVADO Y EL LIBERALISMO POLÍTICO DE J. RAWLS*
}

\author{
Isabel Turégano Mansilla \\ Universidad de Castilla-La Mancha
}

\section{Introducción}

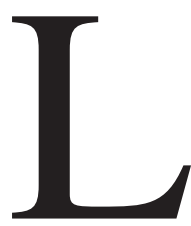

as diversas corrientes del denominado «feminismo de la segunda ola», que se desarrolla a partir de los años sesenta del siglo XX, coinciden en que la consecución de la igualdad de derechos entre hombres y mujeres no ha logrado eliminar la discriminación que subyace a las estructuras sociales en las que aquellos se relacionan. Tanto la teoría feminista liberal como la marxista y socialista adoptan el concepto de patriarcado del feminismo radical conforme al cual la incorporación de las mujeres en el ámbito público se habría producido a costa del mantenimiento de estructuras privadas de subordinación. Por ello se considera que la igualdad exige tanto a la teoría de la justicia como a la teoría política plantearse la discriminación que subyace al sistema económico y laboral, las relaciones familiares, la reproducción, la sexualidad, etc. La teoría política y moral liberal, con su ideal formal de igualdad, habría propiciado una separación u oposición entre lo público y lo privado que perpetúa en este último ámbito relaciones de discriminación.

Se considera que la universalización de los principios liberales conlleva la crisis de los propios presupuestos morales y políticos del liberalismo. En primer lugar, obliga a revisar el alcance de la separación entre los principios de justicia y las exigencias de la «vida buena». En segundo lugar, obliga a reflexionar sobre las formas de participación y representación políticas. Las distintas corrientes feministas han hecho aportaciones diversas a los problemas relativos a la participación política de las mujeres, como el conocido lema radical de que «lo personal es político» o el planteamiento de un nuevo modelo de lo político de autoras como I. M. Young o S. Benhabib.

* Este trabajo ha sido realizado con una ayuda a cargo del Programa Nacional de I+D+I, proyecto BJU2000-0277, del Ministerio de Educación, Cultura y Deporte. 
La influyente versión del liberalismo de John Rawls, sin embargo, ha respondido a alguno de los retos que el feminismo ha lanzado a la doctrina liberal. La radical separación entre lo público y lo privado del contractualismo clásico, que sirvió para excluir del segundo ámbito -al que se vinculaba naturalmente a las mujeres- los principios de libertad e igualdad formal, se ha transformado en las obras más recientes de Rawls en dos espacios conectados a los que son igualmente aplicables los principios de justicia. Sin embargo, frente al acento que las propuestas políticas más críticas de cierto sector del feminismo han puesto en la diferencia, Rawls insiste en la necesidad de la búsqueda de un ámbito de argumentación pública en el que todos los individuos se orienten a lograr un consenso respecto de los principios básicos de justicia.

\section{La crítica feminista a la distinción liberal entre lo público y lo privado}

Gran parte de la crítica feminista a la doctrina liberal se vertebra en torno a su separación u oposición entre lo público y lo privado. El feminismo ha contribuido en gran medida al replanteamiento del significado de estos términos inherentemente ambigüos y de las consecuencias que tiene su definición en relación con la legitimidad de la acción estatal.

A pesar de la variedad de perspectivas y de conclusiones de los estudios feministas, creo que las críticas fundamentales a la dicotomía liberal de lo público y lo privado se han dirigido frente a los siguientes argumentos: la identificación del ámbito público con el ejercicio de la política desde el punto de vista de la razón normativa imparcial y universal; la concepción patriarcal de lo público y de la familia que encubre la anterior perspectiva; el carácter natural, y no cultural o histórico, de las desigualdades entre hombres y mujeres; el derecho a la intimidad como límite infranqueable a la acción estatal; la pretendida igualdad y ausencia de restricciones que caracterizan el contexto en el que las mujeres adoptan libremente sus decisiones; y, finalmente, la concepción excluyente de la política.

\subsection{La razón pública universal}

La escisión liberal entre lo público y lo privado identifica el ámbito público con el ejercicio de la política desde el punto de vista de la razón normativa imparcial y universal. Este es el punto de vista de un observador abstraído de las condiciones histórico-materiales que condicionan la existencia humana, que, en consecuencia, construye el sistema ético eliminando las particularidades de los sujetos y situaciones concretas. La razón solipsista es ajena a las necesidades del sujeto histórico y se expresa en re- 
glas o principios generales que atienden a aquello que es común a toda persona ${ }^{1}$.

En uso de esa razón, el ámbito público está dominado por la imparcialidad y la generalidad. En él, la pluralidad de personas, con necesidades, intereses y deseos contrapuestos, se reduce a un sujeto único titular de derechos universales. La generalidad de la ley se fundamenta en el reconomiento de los intereses comunes y en la posibilidad de la voluntad general rousseauniana. Para ello, se excluyen de la decisión pública aquellos aspectos de la existencia humana que puedan amenazar la unidad. Los sentimientos, afectos, deseos y necesidades particulares dominan la esfera privada. En ella, cada individuo persigue fines propios o compartidos con los miembros de algún grupo o asociación y es el mercado el que resuelve conflictos y logra una armonía social.

El punto de vista racional e imparcial que preside lo político depende de que la necesidad y el sentimiento sean contenidos en el ámbito privado, que es el terreno de la particularidad y la diferencia ${ }^{2}$. La crítica feminista ha puesto de manifiesto cómo a la distinción liberal entre público y privado subyace una pretensión de homogeneidad que excluye la consideración política de las diferencias. Las desigualdades que subsisten en el ámbito privado quedan ocultas bajo la artificial unidad de lo público. En concreto, bajo el manto de la igualdad de oportunidades y libertad de elección se oculta la desventajosa posición de la mujer en el ámbito familiar -fundamentalmente por una desigual división del trabajo doméstico- que restringe la ca-

\footnotetext{
${ }^{1}$ Un sector relevante del feminismo ha opuesto a esta razón normativa universal de inspiración kantiana un modo distinto de razonamiento moral propio de las mujeres. Esta concepción de la moral, que adopta un punto de vista contextual y particularista, ha sido denominada «ética del cuidado y la responsabilidad» frente a la «ética de la justicia y los derechos» (vid. C. GILLIGAN, In a Different Voice: Psycological Theory and Women's Development, Harvard University Press, Cambridge, Mass., 1982; Nel NODDINGS, Caring: A Feminine Approach to Ethics and Moral Education, University of California Press, Berkeley, 1984; L. BLUM, «Gilligan and Kohlberg: Implications for Moral Theory», Ethics, 97, 1988, pp. 472-491. Algunas aclaraciones de Gilligan al significado de su obra en C. GILLIGAN, «Moral Orientation and Moral Development», en E.Feder y D.Meyers, Women and Moral Theory, Rowman and Littetlefield, Totowa, 1987, pp.19-33). Una aproximación crítica a esta concepción de la justicia desde el feminismo se encuentra en W. FLANAGAN y K. JACKSON, «Justice, Care and Gender: The Kohlberg-Gilligan Debate Revisited», Ethics, 97, n. 3, 1987 y S. M. OKIN, Justice, Gender and the Family, Basic Books, New York, 1989, p. 15.

${ }^{2}$ I. M. YOUNG, «Imparcialidad y lo cívico-público. Algunas implicaciones de las críticas feministas a la teoría moral y política», en S.Benhabib y D.Cornell (eds.), Teoría feminista y teoría crítica. Ensayos sobre la política de género en las sociedades del capitalismo tardío, Alfons el Magnànim-IVET, Valencia, 1990, p.103-104; y La justicia y la política de la diferencia, trad. de Silvina Alvarez, Cátedra, Madrid, 2000, cap. IV, pp. 165-205.
} 
pacidad de las mujeres para desarrollar sus propios intereses (económicos, laborales, culturales, etc. $)^{3}$.

Seyla Benhabib ha denominado al punto de vista moral universalista la perspectiva del «otro generalizado» y lo critica, no sólo porque conduce a la privatización de la esfera de las mujeres, sino porque es incompatible con los criterios mismos de reciprocidad y universalidad que pretenden satisfacer los defensores del universalismo. Por una parte, la reciprocidad moral implica la capacidad de adoptar el punto de vista del otro, pero la exigencia de imparcialidad y neutralidad, la total abstracción de su identidad en definitiva, presenta al otro como una máscara vacía difícilmente identificable con seres humanos. El otro tiene una identidad puramente definicional tras la que no existe una verdadera pluralidad humana. Por ello, la reciprocidad en las teorías morales universalistas es incompleta, dado que su principal requisito, es decir, la distinción coherente entre tú y yo, no se puede sustentar en esas circunstancias. Bajo la condición de imparcialidad el otro desapare-

\footnotetext{
${ }^{3}$ A este primer argumento de la crítica feminista subyace un cierto eco de la distinción marxista entre la igualdad formal o jurídica y la igualdad real o fáctica, que implica una desvalorización de la primera por su carácter ideológico y su contribución al mantenimiento de las desigualdades sociales, fundamentalmente económicas (K. MARX (1875), «Crítica al Programa de Gotha», en K. Marx y F. Engels, Obras escogidas, Progreso, Moscú, tomo III, 1976. Vid. F. LAPORTA, «El principio de igualdad: Introducción a su análisis», Sistema, 67, 1985, pp. 27-31). Sin embargo, esta distinción oscurece el papel esencial que puede tener el Derecho tanto en la eliminación de discriminaciones como en el tratamiento diferenciado de situaciones distintas en aspectos relevantes. De este modo, se puede afirmar -en la terminología ampliamente aceptada- que aunque la igualdad ante la ley no coincide con la igualdad sustancial y, en este sentido, es una igualdad insuficiente, los sistemas jurídicos de los Estados de bienestar recogen la exigencia de que la ley tienda a lograr la igualdad real y efectiva. La distinción entre las esferas pública y privada cambió en las sociedades del denominado capitalismo tardío como consecuencia de la mayor actuación del Estado. Ambitos que se habían considerado tradicionalmente propios de la esfera doméstica -tales como la educación, el cuidado de niños y de ancianos, la salud, el aborto, el maltrato a mujeres y menores, la división sexual del trabajo, etc.- comenzaron a tener relevancia jurídica. El Derecho se convierte en un instrumento que puede operar efectivamente a favor de la igualdad real. Esto es así cuando se emplea en políticas de acción «positiva» o «afirmativa» que tienden a eliminar la discriminación injusta que sufren ciertos grupos o colectivos (M. Angeles BARRERE UNZUETA, Discriminación, Derecho antidiscriminatorio y acción positiva a favor de las mujeres, Civitas, Madrid, 1997. R. ALEXY contrapone las acciones «positivas» del Estado social a las acciones «negativas» del Estado liberal clásico en Teoría de los derechos fundamentales, Centro de Estudios Constitucionales, Madrid, 1993, p. 419). Como afirma Barrère, no toda acción positiva que favorezca la igualdad real es necesariamente una discriminación inversa que lesiona derechos fundamentales del individuo a favor de la igualdad de ciertos grupos. Ambas, no obstante, aunque en mayor medida las acción positivas en cuanto menos «discriminatorias», pueden estar éticamente justificadas (ibídem pp.93-96. En el mismo sentido, A. RUIZ MIGUEL, «La discriminación inversa y el caso Kalanke», Doxa, 19, 1996, pp. 123-140). La modificación que sufre la relación entre lo público y lo privado en el Estado de bienestar ha sido tratada desde el feminismo en Anne SHOWSTACK SASSOON (ed.), Las mujeres y el Estado, prólogo de Lidia Falcón, Vindicación Feminista, Madrid, 1996.
} 
ce. Por otra parte, este punto de vista impide la universalización de nuestros juicios morales, puesto que para llevarla a cabo es preciso conocer cuándo las situaciones individuales son semejantes y este razonamiento exige, según Benhabib, abarcar el punto de vista del «otro concreto». Este punto de vista considera a todos y cada uno de los seres racionales como un individuo con una historia, una identidad y una constitución afectivo-emocional concretas. Cuando empleamos esta perspectiva intentamos comprender las necesidades del otro, sus motivaciones y deseos, que nos permitirán conocer si su situación es semejante a la nuestra. La teoría moral universalista descuida este punto de vista y adopta la perspectiva pública de la justicia ${ }^{4}$.

\subsection{La ideología patriarcal}

La crítica feminista no sólo ha puesto de manifiesto el carácter excluyente de la esfera pública como consecuencia de su noción abstracta de persona sino que, además, ha mostrado cómo los ideales liberales de igualdad formal y racionalidad universal están definidos desde la posición dominante del hombre y conforme a su concepción del ser humano y la sociedad. Así, la concepción abstracta de lo público cumple una importante función ideológica que limita la participación de las mujeres en la vida pública, al mismo tiempo que presenta a ésta como un orden universal e igualitario ${ }^{5}$.

\footnotetext{
${ }^{4}$ La autora no pretende centrar la teoría moral y política en torno al «otro concreto» sino que éste es sólo un concepto crítico que designa los límites ideológicos del discurso universalista. En este sentido, defiende un universalismo interactivo como proceso político y moral que no busca un consenso ideal de seres definidos ficticiamente sino que parte de las diferencias entre seres concretos y trata de llegar a un punto de vista aceptable para todos, en la línea de las éticas comunicativas (Seyla BENHABIB, «El otro generalizado y el otro concreto: la controversia Kohlberg-Gilligan y la teoría feminista», en S. Benhabib y D. Cornell (1987), Teoría feminista y teoría crítica, op. cit., pp. 119-149).

${ }^{5}$ Este es uno de los argumentos centrales de la crítica feminista a la dicotomía público/privado. Vid., entre otros, Z. EISENSTEIN, The Radical Future of Liberal Feminism, Longman, New York, 1979; L. J. CLARCK y L. LANGE (eds.), The Sexism of Social and Political Thought, University of Toronto Press, Toronto, 1979; J. ELSHTAIN, Public Man, Private Woman: Women in Social and Political Thought, Princeton University Press, Princeton, 1981; A.JAGGAR, Human Nature and Feminist Politics, Rowman and Allenheld, Totowa, N. J., 1983; C. PATEMAN (1983), «Feminist Critiques of the Public/Private Dichotomy», en Anne Phillips (ed.), Feminism and Equality, New York University Press, New York, 1987, pp.103126; H. PITKIN, Fortune is a Woman, University of California Press, Berkeley, 1984; L. NICHOLSON, Gender and History, Columbia University Press, Nueva York, 1986; C. MACKINNON, Feminism Unmodified: Dicourses on Life and Law, Havard University Press, Cambridge, Mass., 1987; I. M. YOUNG (1987), «Imparcialidad y lo cívico-público», op.cit., pp. 89-117; C. PATEMAN y E. GROSS (eds.), Feminist Challenges: Social and Political Theory, Northeastern University Press, Boston, 1987; S. M. OKIN, Justice, Gender, and the Family, op.cit. En nuestro país, Ana RUBIO CASTRO, «El feminismo de la diferencia: los argumentos de una igualdad compleja», Revista de Estudios Políticos, Nueva Epoca, n. 70, 1990, pp. 185-207.
} 
En el liberalismo clásico, la pretensión de lo público de afirmar la razón normativa como algo universal e imparcial supuso en la práctica la exclusión política de las personas asociadas naturalmente con la afectividad y los sentimientos, como es el caso de las mujeres. Se concibe que el ámbito natural de éstas es el hogar y la vida familiar en la que predominan relaciones de tipo afectivo. En consecuencia, no se consideran aptas para adoptar decisiones públicas racionales. La propia idea de igualdad que subyace a la noción de consenso de los contractualistas clásicos es una igualdad entre los individuos varones, quienes, como en el caso de la teoría de Locke, son los únicos que -en cuanto propietarios- tienen capacidad para contratar ${ }^{6}$.

La crítica feminista considera que la concepción patriarcal de la sociedad que llevó al liberalismo clásico a excluir a las mujeres de lo público, se prolonga en el liberalismo contemporáneo en una visión patriarcal de la dicotomía público/privado. Esta visión no supone, en primer lugar, que las desigualdades entre hombres y mujeres tengan su origen en la incapacidad de las mujeres para competir en un marco de reglas imparciales y universales, sino que supone que tienen su origen en el hecho de que tales reglas han sido definidas de acuerdo con los intereses y valores de los hombres. Los roles y posiciones sociales relevantes han sido definidos de modo tal que los hombres -en cuanto independientes de las cargas familiares- resulten más aptos para ellos y, en consecuencia, la estructura de la sociedad es desigualitaria aunque aparentemente no existan discriminaciones arbitrarias?

En segundo lugar, la distinción liberal entre lo público y lo privado ha excluido de la consideración teórica el ámbito familiar, al que se vincula a la mujer por sus caracteres naturales. Esta exclusión está presente en los dos sentidos que puede adoptar la distinción liberal. El uso que el liberalismo hace de los términos «público»y «privado» es ambigüo ${ }^{8}$. Es posible entender, en primer lugar, que la distinción entre ambas esferas pretende separar la sociedad (incluyendo tanto lo estrictamente social como lo político) de la esfera íntima. Esta última se configura como un refugio del individuo no sólo frente a la coerción estatal sino también frente a las presiones sociales.

${ }^{6}$ Carole Pateman expone cómo en el pensamiento de John Locke existe, con anterioridad al contrato social, un derecho natural de los hombres sobre las mujeres y cómo con el nacimiento de la sociedad civil ese derecho se transforma en un derecho civil patriarcal mediante el contrato de matrimonio [C. PATEMAN (1988)], El contrato sexual, Anthropos, Madrid, 1995).

${ }^{7}$ Catharine A. MACKINNON, Feminism Unmodified, op. cit., pp. 32-45; S. M. OKIN, Justice, Gender, and the Family, op. cit.

${ }^{8}$ En lo que sigue adopto las distinciones de C. PATEMAN, «Feminist Critiques of the Public/Private Dichotomy», op. cit., pp. 106-108 y Will KYMLICKA (1990), Filosofía política contemporánea. Una introducción, trad. de R. Gargarella, Ariel, Barcelona, 1995, pp. 273-287. 
Es el ámbito de las relaciones íntimas tales como el parentesco, el amor, la amistad o el sexo, que está protegido por el Derecho mediante el derecho a la intimidad.

Tradicionalmente se ha considerado que la vida familiar pertenece a esa esfera de intimidad y goza, consecuentemente, de inmunidad frente al control social y político. En cuanto ámbito privado, la familia se fundamenta en principios distintos de los que están en la base de la esfera pública: mientras que la participación en esta última está presidida por los principios liberales universales (igualdad, propiedad, libertades), la vida familiar está presidida por relaciones de subordinación que se consideran connaturales a la distinción entre hombres y mujeres. La teoría liberal ha creido posible definir universalmente el mundo público como una esfera igualitaria haciendo abstracción de las relaciones de dominación que perduran en la vida familiar. La crítica feminista no cuestiona el carácter privado de la esfera doméstica, pero muestra cómo ésta se interrelaciona con la vida social y política. Esto es así no sólo porque las desigualitarias relaciones familiares limitan en gran medida la plena participación de la mujer en lo público, sino también porque en muchos casos la intimidad de la familia sirve para encubrir la violación de derechos esenciales del individuo. Ello es fruto de la confusión entre un concepto descriptivo y uno normativo de lo privado, al que me referiré más adelante.

La distinción liberal se puede entender en un segundo sentido. Partiendo de la separación anterior, se reestablece la división entre lo público y lo privado en el seno de la propia sociedad, dejando a un lado la vida doméstica. Así entendida, la distinción se ha expresado en diferentes binomios: Estado y sociedad, política y economía, coerción y libertad, político y social, en los que la categoría que hace referencia a lo privado prevalece sobre la referente a lo público. Como ha puesto de manifiesto Kymlicka, el ideal liberal de la vida privada no era el de proteger al individuo frente a la sociedad, sino el de liberar a la sociedad de la interferencia política. El liberalismo ensalza el asociacionismo y la cooperación. Lo social es el ámbito en el que el individuo puede perseguir libremente sus intereses privados, mientras que la fuerza y la violencia es el monopolio del Estado.

Esta conceptualización de la sociedad civil al margen del Estado deja fuera a la familia, por lo que ésta acaba siendo olvidada de la discusión teórica. La separación entre lo privado y lo público se presenta así como una división en el seno de lo que, conforme al primer sentido al que he hecho referencia, era el mundo de los hombres. Por ello, las críticas feministas insisten en que cualquier alternativa al concepto liberal de lo político, como las propuestas de reintegrar la política en el ámbito social de Wolin o Habermas, no pueden olvidar la relación entre lo social y la vida doméstica. La 
idea de una esfera pública despolitizada (lo social o lo económico) tuvo desde el principio un significado patriarcal, al excluir de la consideración teórica y práctica la vida doméstica a la que se vinculaba naturalmente a la mujer. Esta escisión de la esfera social y familiar sirve para perpetuar en la segunda la desigual distribución del poder y del trabajo al remitir la igualdad exclusivamente a la esfera social. Al mismo tiempo, la desigualdad de la esfera familiar se proyecta en una desigualdad social: la división sexual del trabajo doméstico perpetúa la dependencia económica de la mujer que se ve obligada a elegir trabajos a tiempo parcial o peor remunerados y, en cualquier caso, tiene menor capacidad para perseguir libremente sus propios intereses.

En todo caso, por tanto, la teoría liberal ha desatendido las relaciones internas de la familia y no se ha planteado la vinculación entre lo doméstico y lo público, al mismo tiempo que se ha mostrado reticente a juzgar la vida doméstica a la luz de los criterios de justicia. Como ha puesto de manifiesto S.Benhabib, los primeros teóricos del contrato distinguen entre la justicia y la vida buena; es decir, entre los principios morales dirigidos a la resolución de conflictos interpersonales o sociales y las especiales exigencias de cuidado que están relacionadas con dominios más personales, tales como el parentesco, el amor, la amistad o el sexo. Las demandas de la justicia sientan las bases para la cooperación social, mientras que las exigencias de la vida buena son definidas por el sujeto autónomo conforme a su propia conciencia. Es esta distinción entre justicia y vida buena la que está en la base de la escisión entre público y doméstico9. La crítica feminista ha llamado la atención sobre la necesidad de que la teoría de la justicia, así como la filosofía política, se ocupe de la estructura de la familia ${ }^{10}$.

Sorprende que, conforme al segundo de los sentidos de la distinción liberal entre público y privado -aquel que distingue lo político de lo socialse excluya del segundo a la familia, que se puede considerar la institución social paradigmática, «en principio basada en ese tipo particular de cooperación que los liberales admiran en el resto de la sociedad, pero que hoy se encuentra todavía estancada en razón del tipo de restricciones propias del feudalismo, que los liberales aborrecen ${ }^{11}$. El argumento con el que se ha

${ }^{9}$ Seyla BENHABIB, «El otro generalizado y el otro concreto», op. cit., pp. 127-135. La autora ha criticado más recientemente la vinculación de las cuestiones de justicia con la esfera pública universal que lleva a cabo el liberalismo en «Models of Public Space: Hannah Arendt, the Liberal Tradition and Jürgen Habermas», en C. Calhoum (ed.), Habermas and the Public Sphere, Cambridge, MIT, 1993.

${ }^{10}$ Vid., entre otras, J. B. ELSHTAIN, Public Man, Private Woman, op.cit.; S. M. OKIN, Justice, Gender and the Family, op. cit.; y C. PATEMAN, «Feminist Critiques of the Public/Private Dichotomy», op. cit.

${ }^{11}$ W. KYMLICKA, Filosofía política contemporánea, op. cit., p. 276. 
tratado de justificar esta actitud excluyente ha sido la vinculación de las mujeres con la naturaleza.

\subsection{El carácter natural de las desigualdades entre hombres y mujeres}

La desigual posición de las mujeres y los hombres en la vida familiar se ha tratado de justificar en virtud de argumentos de naturaleza antropológica y biológica. Los primeros descansan en el dualismo entre naturaleza y cultura. La devaluación del trabajo doméstico y de la crianza de los hijos deriva de que son consideradas tareas puramente naturales, mientras que el objetivo de la humanidad consiste en trascender la existencia natural para desarrollar actividades culturales. La vinculación de la mujer con los niños y la casa las aproxima a la naturaleza y las subordina necesariamente al hombre que desempeña las actividades de carácter más elevado ${ }^{12}$.

En la mayoría de casos, el confinamiento de las mujeres a la vida doméstica se ha justificado con argumentos que parten del hecho biológico de la procreación para afirmar la naturaleza afectiva, particularista o emocional de las mujeres que las incapacita para la toma de decisiones públicas ${ }^{13}$.

Algunas feministas han puesto de manifiesto cómo la reducción de la justificación de las desigualdades sociales a argumentos acerca de la naturaleza conduce a un callejón sin salida. El camino adecuado ha de encontrarse desde una perspectiva que tenga en cuenta las relaciones sociales entre mujeres y hombres en estructuras históricas de subordinación ${ }^{14}$. J.S.Mill ya criticó la apelación a la naturaleza para justificar una excepción a los principios liberales de libertad e igualdad. Afirmó que no es posible conocer si existen o no diferencias naturales entre hombres y mujeres hasta que no podamos conocer sus respectivos atributos en el seno de relaciones e instituciones igualitarias distintas de las relaciones históricas de subordinación ${ }^{15}$.

\subsection{La intimidad en sentido normativo}

La separación de lo público y lo privado, en cualquiera de los dos sentidos a los que he hecho referencia, los presenta como dos ámbitos herméti-

\footnotetext{
12 Vid. S. B. ORTNER, «Is Female to Male as Nature is to Culture», en M. Z. Rosaldo y L.Lamphere (eds.), Women, Culture and Society, Stanford University Press, Stanford, 1974.

13 Veánse las obras de E. KENNEDY y S. MENDUS, Women in Western Political Philosophy, Wheatsheaf Books, Brighton, 1987; S. OKIN, «Women and the Making of the Sentimental Family», Philosophy and Public Affairs, 11/1, 1981, pp. 65-88; Alison JAGGAR, Feminist Politics and Human Nature, op. cit.

${ }^{14}$ C. PATEMAN, «Feminist Critiques of the Public/Private Dichotomy», op. cit., p. 112.

15 J. S. MILL, «La discriminación de la mujer», en J.S.Mill y H.Taylor, La igualdad de los sexos, trad.de Jesús Villa y Sofía Martín-Gamero, Ed.Guadarrama, Madrid, 1973, pp. 107-108.
} 
cos, desconectados entre sí y presididos por principios distintos: el primero está gobernado por principios racionales universales -fundamentalmente la igualdad y la libertad formales- mientras que el segundo está presidido por relaciones de dominación y por el reparto desigualitario de las cargas. Al mismo tiempo se ha empleado esta separación para marcar los límites de la acción estatal: no se considera un uso legítimo de la coerción el que afecta a la vida privada de las personas. Puesto que lo íntimo se estima propio de la vida privada, se ha considerado que las acciones llevadas a cabo en la intimidad del hogar son inmunes a la intervención estatal.

La crítica feminista ha puesto de manifiesto, sin embargo, que esta conclusión confunde varios significados de lo privado ${ }^{16}$. En primer lugar, confunde aquello que es íntimo y aquello que sólo afecta al propio individuo. Las acciones privadas que han de constituir el límite de la acción estatal legítima son las acciones que no causan daños a terceros. Confundirlas con las acciones que se llevan a cabo en la intimidad conlleva el riesgo de que el Estado tolere graves actuaciones en el seno de la familia, tales como la violencia doméstica o la desigual distribución de cargas y responsabilidades.

En segundo lugar, y derivado de lo anterior, las relaciones familiares sólo se pueden considerar privadas en un sentido descriptivo y no en un sentido normativo. Lo privado, en sentido descriptivo, hace referencia a la vinculación con el individuo (bien porque sea algo íntimo, porque se relacione con la propia identidad o porque sólo afecte al propio individuo) y en un sentido normativo hace referencia a aquello que no debería regularse por el Estado. Afirmar que la vida familiar es una esfera íntima y, por tanto, privada en un sentido amplio, como reconocen las autoras feministas, no implica necesariamente que deba excluirse de la coerción estatal. Lo doméstico sería privado sólo en un sentido descriptivo y no normativo, al menos hasta que se presuma que se trata de relaciones consensuadas o voluntarias.

\subsection{Autonomía de la elección individual}

Esa presunción de voluntariedad implica un riesgo para las teorías políticas fundadas en la autonomía y el consentimiento individuales. El uso de la noción de consentimiento como justificación de una acción exige que el individuo cuente con la información, opciones y falta de coacción suficien-

\footnotetext{
${ }^{16}$ Para una clasificación de los distintos significados del binomio público/privado, que en parte sigo a continuación, vid. S. I. BENN y G. F. GAUS, «The Liberal Conception of the Public and Private», en la obra colectiva edictada por las propias autoras Public and Private in Social Life, Croom Helm, Kent, 1983, p. 31; y Ruth GAVISON, «Feminism and the Public/Private Distinction», Stanford Law Review, 45, 1, 1992, pp. 1-45.
} 
tes para que su decisión de actuar se pueda considerar autónoma. El feminismo ha criticado al liberalismo por aceptar como elecciones libres aquellas que están condicionadas por numerosos factores exógenos. En él, «la imposibilidad de elegir deviene en elecciones libres» ${ }^{17}$. Las decisiones que adoptan las mujeres pueden estar condicionadas por coerciones de distinto tipo que nos obligan a plantearnos su carácter autónomo. Así, por ejemplo, no es una elección libre la de la mujer que opta por permanecer en el hogar a pesar de sufrir violencia marital. Sería interesante, en este sentido, tener en cuenta las investigaciones sobre la formación de preferencias llevadas a cabo por J.Elster y C.Sunstein ${ }^{18}$.

\subsection{Concepción excluyente de la política}

El movimiento político de las mujeres, del mismo modo que el resto de movimientos sociales de las últimas décadas del siglo XX, ha sometido a crítica la teoría política individualista liberal, proponiendo una concepción alternativa de la democracia. En ésta, la drástica separación entre lo público y lo privado se disuelve en un espacio público en el que los intereses y las creencias particulares sustituyen el individualismo abstracto y el universalismo del pensamiento liberal.

El lema del feminismo radical «lo personal es político» no supone, en todos los casos, la negación de la distinción entre lo público y lo privado, pero sí pone de manifiesto la estrecha vinculación entre ambas esferas. Y ello en dos sentidos. En primer lugar, la posición de subordinación de la mujer en lo privado afecta directamente a su integración plena e igual en lo público y, en este sentido, ha de considerarse un asunto político. La igualdad formal lograda con el sufragio universal no se ha reflejado en una proporcionalidad en la representación política debido, entre otras cosas, a la situación inicial de reparto desigualitario de las responsabilidades y cargas en el ámbito doméstico. Por tanto, la redistribución igualitaria de las responsabilidades familiares es una exigencia democrática y no sólo privada o social $^{19}$.

En segundo lugar, ni siquiera es cierto, como mantiene el liberalismo, que el Estado no intervenga en la vida personal y familiar. La familia ha sido siempre una preocupación del Estado cuya regulación del matrimonio y

17 C. A. MACKINNON, Feminism Unmodified, op. cit., p. 137.

18 Vid. J. ELSTER (1983), Uvas amargas, Península, 1988, y C. SUNSTEIN, «Preferences and Politics», Philosophy and Public Affairs, 3, 1991, pp. 3-34. La propuesta es de R. GARGARELLA, Las teorías de la justicia después de Rawls, Paidós, Barcelona, 1999, pp. 88-89.

${ }^{19}$ Anne PHILLIPS, «¿Qué tiene de malo la democracia liberal?», en Género y teoría democrática, Universidad Nacional Autónoma de México. Recopilado en R. del Aguila, F. Vallespín y otros, La democracia en sus textos, Alianza, Madrid, 1998, pp. 328-329. 
la sexualidad presupone y mantiene la posición subordinada de la mujer ${ }^{20}$. Muchas de las circunstancias personales de las mujeres dependen de factores públicos, tales como las regulaciones jurídicas sobre los métodos anticonceptivos, el aborto, la violación, el matrimonio, políticas de bienestar sobre el cuidado de niños o ancianos, posición de la mujer en la esfera laboral, etc. «Así, los problemas "personales" sólo se pueden resolver mediante medios políticos y acciones políticas» ${ }^{21}$.

Un sector relevante del feminismo no se ha limitado, sin embargo, a mostrar las consecuencias políticas de las relaciones privadas y la incidencia de factores públicos en la situación personal de las mujeres, sino que ha tratado de ir más allá planteando una concepción alternativa de la política, que, en cierto modo, implica la disolución de la separación entre lo público y lo privado. Se pretende una generalización de la democracia a todos los aspectos de la vida como revitalización de la vida pública.

Por una parte, algunas autoras propugnan la extensión de los ideales democráticos a todas las relaciones sociales, no sólo las estrictamente políticas. Se suele criticar a la democracia liberal por el carácter limitado de sus ideales, que prácticamente se reducen al igual derecho al voto. A pesar de reconocer la importancia de éste, se exige que la igual relevancia de toda persona inspire no sólo el ámbito del Estado, sino también el del hogar, la educación, el trabajo, etc. Anne Phillips afirma que «una sociedad verdaderamente democrática sería aquella en la que la gente se apoya entre sí con mutuo respeto y en la que todas las relaciones, no importa lo pequeño o íntimo del contexto, están impregnadas del principio de que cada persona tiene igual peso $»^{22}$. Lo que se ha denominado la «democratización de la vida cotidiana» llama la atención sobre la importancia de que la igualdad democrática inspire cada esfera de la existencia humana. Y ello supone cuestionar la validez de la distinción entre la igualdad pública y la subordinación privada. Las relaciones familiares son una excepción injustificable a los principios liberales de libertad e igualdad individuales que rigen el resto de instituciones políticas y sociales.

Además de la democratización de todas las relaciones sociales, desde los años ochenta algunas autoras tratan de construir una «crítica total» ${ }^{23}$ a la concepción liberal de lo público, mostrando el camino hacia una política de la heterogeneidad. La esfera pública se concibe como un espacio abierto a

${ }^{20}$ Vid. F. E. OLSEN, «The Myth of State Intervention in the Family», University of Michigan Journal of Law Reform, 18, n. 4, 1985; L. J. NICHOLSON, Gender and History, op.cit., intr. y part.3; S.M.OKIN, Justice, Gender and the Family, op. cit., pp. 129-131.

${ }^{21}$ C. PATEMAN, «Feminist Critiques of the Public/Private Dichotomy», op. cit., p. 117.

22 A. PHILLIPS, «¿Qué tiene de malo la democracia liberal?», op. cit., p. 331.

${ }^{23}$ C. PATEMAN, «Feminist Critiques of the Public/Private Dichotomy», op. cit., p. 122. 
la discusión y al debate, en el que los individuos y los grupos puedan afirmar sus diferencias y exigir tanto la satisfacción de sus necesidades específicas como la compensación por las desventajas sufridas por una anterior situación de discriminación ${ }^{24}$. El modo en que se pretende que la vida pública no excluya a personas y grupos es reconociendo su especificidad e introduciendo sus necesidades e historias específicas en la discusión pública. No se niega la separación entre lo público y lo privado, sino la división social entre una esfera pública y una privada, con tipos diferentes de instituciones, actividades y atributos humanos. De ello se derivan dos principios: a) no se debe excluir a priori ninguna institución o práctica social como tema propio de discusión y expresión públicas; y b) no se debe obligar a la privacidad a ninguna persona, acción o aspecto de la vida de una persona. La cuestión de establecer dónde debería fijarse la línea de lo privado es, en consecuencia, una cuestión pública ${ }^{25}$.

La política se concibe como un medio para la discusión y la representación de intereses diversos e individuales. El individuo se implica en lo colectivo y, de este modo, lo personal puede discutirse en la vida pública. Las autoras insisten en la diferencia y la heterogeneidad como fundamento de una democracia más participativa y más activa que no sea excluyente ${ }^{26}$.

Young afirma, en este sentido, que el ámbito público debe suponer el ejercicio de la política conforme a una razón dialógica y no deontológica. Es decir, concibe la política no como la búsqueda de principios imparciales

${ }^{24}$ Ello no implica, como señala I.M.Young, que el debate público deba restringirse a las cuestiones distributivas sino que debería permitir la participación activa sobre cuestiones de fondo relativas a la organización y objetivos de la producción, las estructuras y procedimientos de toma de decisiones y otras cuestiones institucionales similares. La autora coincide con Habermas en sostener que en la sociedad capitalista de bienestar la esfera pública se vuelve cada vez más despolitizada, lo que implica la fragmentación de la vida social y la privatización de la relación de la ciudadanía con el Estado (I. M. YOUNG, La justicia y la política de la diferencia, op. cit., cap. III, pp. 115-163).

25 I. M. YOUNG, «Imparcialidad y lo cívico público», op. cit., pp. 112-117; y La justicia y la política de la diferencia, op. cit., especialmente caps. IV y VI, pp. 165-205 y 263-321. Vid. también S. BENHABIB, «El otro generalizado y el otro concreto», op. cit., pp. 143-149; y «Models of Public Space: Hannah Arendt, the Liberal Tradition, and Jürgen Habermas», op. cit. Este debate feminista se enmarcaría en las discusiones relativas a los problemas derivados de la diversidad cultural de las sociedades modernas que se llevan a cabo desde el «multiculturalismo». Vease, por ejemplo, la crítica al liberalismo de Charles TAYLOR, El multiculturalismo y «la política del reconocimiento», trad. de Mónica Utrilla de Neira, Fondo de Cultura Económica, México, 1993.

${ }^{26}$ Continuando la tradición clásica de Rousseau y J.S.Mill, se atribuye un valor intrínseco a la participación democrática como medio para el desarrollo y el ejercicio de las capacidades de los individuos. También se considera que la democracia es una condición para que la participación pública alcance decisiones justas (I. M. YOUNG, La justicia y la política de la diferencia, op. cit., cap. III, pp. 156-163). 
y universales desde una posición monológica, sino como la búsqueda racional de un entendimiento mediante el diálogo entre una pluralidad de individuos. A pesar de la evidente inspiración de esta concepción emancipatoria de la política en la ética comunicativa de Habermas, este sector del feminismo ha mostrado los límites de la razón dialógica de ésta como razón no contextualizada, para la que las perspectivas particulares quedan neutralizadas como condición de posibilidad del consenso ${ }^{27}$.

\section{Público y privado en El liberalismo político de Rawls}

Deseo a continuación circunscribir el análisis de la teoría de John Rawls a tres de los aspectos que el feminismo ha criticado a la dicotomía liberal entre público y privado ${ }^{28}$. Asimismo limito mi análisis a los escritos más recientes del autor estadounidense, fundamentalmente su Liberalismo político, a partir del cual sus referencias a la dicotomía citada son más explícitas $\mathrm{y}$ adquieren un nuevo significado ${ }^{29}$. Muestro, en primer lugar, que la teoría

${ }^{27}$ Vid. I. M. YOUNG, «Imparcialidad y lo cívico público», op. cit., pp. 105-107; y La justicia y la política de la diferencia, op. cit., pp. 181-183, 197-205. Algunos comentarios feministas al pensamiento de Habermas se encuentran en N. FRASER, «¿Qué tiene de crítica la teoría crítica? Habermas y la cuestión del género», en S. Benhabib y D. Cornella, Teoría feminista y teoría crítica, op.cit., pp.49-88; y J. MEEHAN, Feminist Read Habermas. Gendering the Subject of Discourse, Routledge, Nueva York, 1995.

${ }^{28}$ Respecto de los demás argumentos de la crítica feminista, creo que Rawls argumentaría del siguiente modo: En relación con la crítica al carácter natural que se atribuye a las desigualdades entre hombres y mujeres (apartado 1.3.), Rawls reconoce en El liberalismo político que los problemas de género son uno de los problemas característicos de la vida política contemporánea. De esta manera el sexo y el modo en que se concibe por las instituciones políticas y sociales no es concebido como un rasgo natural a ser eliminado del debate público, sino como uno de los problemas básicos a los que se ha de aplicar su concepción política de la justicia. Respecto del apartado 1.4. relativo a la intimidad en sentido normativo, Rawls ha insistido recientemente en que el ámbito no público no implica un límite a la aplicación de sus principios de la justicia. Las asociaciones en las que se inserta el individuo -entre las que se encuentra la familia- están sujetas a restricciones esenciales derivadas de la justicia (J. RAWLS, «The Idea of Public Reason Revisited», The University of Chicago Law Review, vol. 64, n. 3, verano 1997, p. 791). En relación con la presunción de autonomía de la elección individual (apartado 1.5), como ha puesto de manifiesto Gargarella, Rawls se ha referido recientemente al problema de la voluntariedad de las elecciones (R. GARGARELLA, Las teorías de la justicia después de Rawls, op. cit., p. 89). La cuestión, según Rawls, implica distinguir entre lo racional y lo razonable. Una elección puede ser voluntaria en el sentido de racional aunque conlleve condiciones inequitativas; pero sólo será voluntaria en el sentido de razonable cuando las condiciones en las que se adopta son todas ellas equitativas. En el texto interpreta la voluntariedad en el segundo sentido (J. RAWLS, «The Idea of Public Reason Revisited», op. cit., p. 792 n. 68).

${ }^{29}$ La explicación que Rawls hacía del género y de la familia en Teoría de la justicia ha recibido numerosas críticas desde el feminismo. Vease Jane ENGLISH, «Justice between Generations», Philosophical Studies, 31, 1977, pp. 91-104; Deborah KEARNS, «A Theory of Justice and Love; Rawls on the Family», Politics, 18, 1983; pp. 36-42; Karen GREEN, «Rawls, 
política de Rawls emplea una argumentación trascendental con pretensión de validez universal, que limitará los aspectos deliberativos de su teoría de la democracia. En segundo lugar, niego que tal pretensión de universalidad suponga una ideología patriarcal. La identificación de lo público con la razón universal que lleva a cabo Rawls no convierte a la esfera privada en una espacio exento de justicia. Por último, contrapongo a la «política de la diferencia» que propone I. M. Young la visión rawlsiana secularizada y universalista de la vida pública, separada de la diversidad de la sociedad civil. Por consiguiente, sólo en el segundo de los aspectos citados -la extensión de la concepción de la justicia a las esferas no políticas- la teoría de Rawls coincidiría con la crítica feminista, con la que discrepa, sin embargo, en su concepción contextual y particularista del razonamiento moral y su noción participativa de la democracia.

\subsection{Teoría política universalista}

En la teoría política y moral de Rawls la razón pública se identifica con un punto de vista imparcial y universal. A pesar del esfuerzo de Rawls por tener en cuenta la pluralidad de sujetos morales, como trataré de argumentar en el apartado 3.3., su «posición originaria» tiene un carácter monológico que va a condicionar el proceso deliberativo real.

Además, a pesar de la vinculación de la teoría política rawlsiana con los valores políticos de las democracias constitucionales reales, no logra desprenderse de una argumentación de carácter trascendental. No ha sido ésta la interpretación de Bruce Ackerman, quien ha criticado el conservadurismo de El liberalismo político por ser una reconstrucción de la moralidad política de las sociedades democráticas y ha defendido el carácter utópico del liberalismo, ya que «ninguna nación sobre la tierra ha alcanzado el tipo de justicia social al cual aspira el liberalismo político» ${ }^{30}$. Así interpretada la

Women and the Priority of Liberty», Australasian Journal of Philosophy, suplemento al vol. 64, 1986, pp. 26-36; S.M.OKIN, Justice, Gender and the Family, Basic Books, New York, 1989, esp. cap. 5, pp. 89-109. Las críticas se centraban en tres aspectos de su teoría: en primer lugar, las personas que participan en la posición original se conciben, no como individuos aislados, sino como «cabezas de familia», lo cual implica limitaciones para el análisis de la justicia en las relaciones familiares. En segundo lugar, se critica la falta de referencia al género como característica individual que ha de quedar oculta bajo el velo de la ignorancia. Por último, el papel fundamental que se atribuye a la familia en la educación moral y la formación del sentido de la justicia no va acompañado por una preocupación por la justicia de la estructura familiar que el desempeño de aquel papel exigiría. En definitiva, Rawls parte de la presunción de que la familia tradicional es justa, a pesar de que, de hecho, esté en contradicción con las principales exigencias de la justicia como equidad. De este modo, se adhiere a la distinción liberal entre lo público y lo privado.

${ }^{30}$ B. ACKERMAN, «Liberalismos políticos», Doxa, 17-18, 1995, pp. 38-49. 
obra de Rawls, la moralidad política se racionalizaría con el recurso al «equilibrio reflexivo» mediante el que los valores políticos de una sociedad y los principios morales intuitivos se someten a un proceso continuo de ajustes y reajustes mutuos. El concepto de «razonabilidad» se opone al de «verdad». El liberalismo político no es una teoría moral comprehensiva ni de ella es posible predicar su verdad, sino que sólo es una concepción política razonable, en el sentido de que está constituida por pretensiones justificables en virtud de su generalidad y reciprocidad. En sus propias palabras, la justicia como equidad «surge de la tradición de pensamiento liberal y de la amplia comunidad de cultura política de las sociedades democráticas y pertenece a ellas. Así que no acaba de ser propiamente formal ni verdaderamente universal... Como doctrina política, la justicia como equidad no quiere formar parte de ninguna teoría comprehensiva de la forma y los presupuestos estructurales del pensamiento y la acción. Como he dicho, persigue más bien dejar estas doctrinas tal como están y las critica sólo en la medida que no son razonables políticamente hablando ${ }^{31}$.

Sin embargo, como ha puesto de manifiesto Vallespín, la argumentación de Rawls sigue incorporando una argumentación trascendental y, en este sentido, su teoría política pretende imponerse con validez universal. Rawls parece sostener, no sólo que su concepción política de la justicia es la que, tras un ponderado juicio, compartimos de hecho en las sociedades democráticas, sino que es la que deberíamos aceptar si queremos una sociedad política democrática y justa. A juicio de Vallespín, Rawls afirma implícitamente que «una vez que reflexionamos sobre la validez moral de las normas público-políticas inexorablemente hemos de incorporar una serie de presupuestos que se nos imponen como necesarios a la razón; no porque sean normas que están ahí latentes en nuestra sociedad y se ajustan a determinadas convenciones morales, sino porque así lo exige su misma naturaleza de normas políticas básicas dentro de un sistema constitucional y democrático. La justificación a partir de la reconstrucción de la normatividad política propia de nuestra sociedad ha de convivir, pues, con esta justificación de tipo trascendental $»^{32}$.

\subsection{La «primacía de lo justo»}

El liberalismo político de John Rawls surge, fundamentalmente, como un intento de resolver el problema que la concepción de la justicia de Teo-

31 J. RAWLS, «Réplica a Habermas», en J. HABERMAS y J. RAWLS, Debate sobre el liberalismo político, trad. de Gerard Vilar Roca, Paidós, Barcelona, 1998, pp. 141-142.

${ }^{32}$ F. VALLESPÍN, Introducción a J. HABERMAS y J. RAWLS, Debate sobre el liberalismo político, op. cit., pp. 21-23. Vallespín coincide aquí con la crítica de Habermas a Rawls en «Reconciliación mediante el uso público de la razón», recopilado en el mismo volumen, p. 55. 
ría de la justicia planteaba para la estabilidad de las sociedades pluralistas. En ésta se partía de la idea irrealista de que en una sociedad bien ordenada todos los ciudadanos podían aceptar la doctrina moral comprehensiva de la justicia como equidad. «El liberalismo político parte del supuesto de que, a efectos políticos, una pluralidad de doctrinas comprehensivas razonables pero incompatibles es el resultado normal del ejercicio de la razón humana en el marco de las instituciones libres de un régimen consitucional democrático» ${ }^{33}$. A partir de ahí, el liberalismo político se define como una concepción política de la justicia para un régimen constitucional democrático que pueda ser aceptada por la pluralidad de doctrinas filosóficas y morales comprehensivas razonables.

Como quedaba expuesto en Teoría de la justicia, el objeto de esta concepción política es la «estructura básica» de la sociedad, es decir, «las instituciones políticas, sociales y económicas principales de una sociedad, así como el modo en que se casan unas con otras en un sistema unificado de cooperación social desde una generación hasta la siguiente» ${ }^{34}$. Entre esas instituciones que «tienen efectos sociales profundos y a largo plazo y modelan de forma fundamental el carácter y los propósitos de los ciudadanos, los tipos de personas que son y que aspiran a ser» ${ }^{35}$ la familia habría de constituir un ejemplo paradigmático. Y, de hecho, Rawls la menciona explícitamente en esta obra como parte de la estructura básica a la que van dirigidos los principios de justicia ${ }^{36}$. En su introducción, reconoce que entre las cuestiones fundamentales que había dejado de lado en su obra anterior se encontraba la de la justicia en la familia, aunque afirma que asumía de alguna manera que era una institución justa.

Rawls cree que las críticas que se dirigieron a su concepción de la justicia por implicar una distinción entre lo público y lo privado ineficaz para enfrentarse a los problemas de género y de familia pueden superarse. Ello es posible si se tiene en cuenta que la concepción de la justicia como equidad se limitaba a una serie de problemas básicos a partir de cuyo análisis se podían adquirir los principios razonables para abordar problemas ulteriores. De lo que parece deducirse que los problemas de género y de familia que no son tratados en Teoría de la justicia han de ser analizados a la luz de los mismos principios razonables de justicia que allí se exponían. «La misma igualdad de la Declaración de Independencia que Lincoln invocó para con-

33 John RAWLS (1993), El liberalismo político, trad. cast. de Antoni Domènech, Crítica, Barcelona, 1996, introducción, p. 12.

34 Ibídem p. 41.

35 Ibídem p. 99.

36 Ibídem p. 293. 
denar la esclavitud puede invocarse para condenar la desigualdad y la opresión sufrida por las mujeres» ${ }^{37}$.

Sin embargo, Rawls no llega a aplicar en Liberalismo político su concepción de la justicia a los problemas familiares y de género y, por el contrario, algunos aspectos centrales de su obra sugieren que la justicia como equidad se aplica sólo al ámbito de lo político y que éste debe distinguirse de lo personal, lo asociativo y lo familiar ${ }^{38}$.

Es cierto que en El liberalismo político se aprecian algunos cambios significativos tendentes a hacer su teoría de la justicia más imparcial en cuestiones de género. Así, al hablar de la justicia intergeneracional abandona su referencia a los «cabezas de familia $»^{39}$ que implicaba una visión tradicional y patriarcal de la misma. Asimismo, Rawls corrige una de las deficiencias fundamentales en materia de género de su anterior concepción de la posición original. Puesto que los participantes en el acuerdo conocen los hechos generales de la sociedad humana deberían conocer que está estructurada en función del género. Por ello, determinar si conocen o no su sexo es lo suficientemente relevante para ser mencionado. A pesar de omitir este aspecto en Teoría de la justicia, ahora Rawls extiende el velo de la ignorancia a la información sobre el sexo y el género de las personas ${ }^{40}$. De hecho, en su introducción había señalado que los problemas de la vida política contemporánea son muy distintos de los que preocuparon al liberalismo en sus orígenes. Entre los problemas actuales más básicos cita los raciales, étnicos y de género ${ }^{41}$.

A pesar de estas modificaciones, parece que en El liberalismo político la esfera doméstica sigue quedando fuera de la concepción de la justicia. Lo que Rawls pretende poner de manifiesto en esta obra es, en definitiva, que la resolución del problema de estabilidad de las sociedades pluralistas exige separar lo político como núcleo de la justicia. Así, insiste en la naturaleza pública y política de las instituciones de la estructura básica y sugiere que las familias no necesitan estar reguladas por los principios de justicia, puesto que se rigen por valores morales propios. Rawls afirma que la concepción política de la justicia no niega que haya otros valores que se apli-

\footnotetext{
${ }^{37}$ Ibídem introducción pp. 24-25.

${ }^{38}$ En el mismo sentido, S. M. OKIN, «Political Liberalism, Justice, and Gender», Ethics, 105, 1994, pp. 26-27.

39 J. RAWLS, El liberalismo político, op. cit., pp. 308, 310. Rawls sustituye la exigencia de que las partes tuvieran en consideración a sus descendientes por la condición de que deben acordar aquel principio de ahorro que todas las generaciones anteriores hubieran seguido.

40 Ibídem p. 55.

41 Ibídem p. 24.
} 
quen al ámbito personal, familiar o asociacional ${ }^{42}$ y considera que cada uno de estos ámbitos están presididos por un tipo de razón distinta de la razón pública $^{43}$.

Ello supone que hay un ámbito diferenciado de lo político, distinto de lo asociacional, que es voluntario de un modo en que no lo es lo político; y distinto de lo personal y de lo familiar, que tienen una dimensión afectiva de la que carece lo político ${ }^{44}$. Ese ámbito de lo político se identifica por su carácter involuntario -necesariamente nacemos en el marco de una estructura social dada de la que sólo salimos al morir- y por su carácter coercitivo respaldado por el uso estatal de sanciones ${ }^{45}$. El modo en que una sociedad política discute y formula sus asuntos es por medio de la razón pública, que implica que «los ciudadanos tienen que llevar a cabo sus discusiones fundamentales en el marco de lo que cada uno considera como una concepción política de la justicia basada en valores cuya aceptación por otros quepa razonablemente esperar, y de modo que cada uno esté dispuesto a defender esa concepción así entendida ${ }^{46}$. Rawls considera que los principios sobre los que se produciría un acuerdo en la posición originaria son los que corresponden a su concepción de la justicia como equidad.

Una concepción política de la justicia-que podemos calificar como «ética pública»- se elabora con el fin de ser el núcleo de un consenso entre las doctrinas religiosas, filosóficas y morales particulares -a las que nos podemos referir como «ética privada»-47. A partir de aquí me interesa, en primer lugar, exponer los rasgos característicos de la ética pública rawlsiana y su relación con las éticas privadas o, como él las denomina, las doctrinas filosóficas y morales comprehensivas. Lo anterior me permitirá, en segundo lugar, mostrar si efectivamente la concepción de la justicia como equidad es estrictamente política y en qué medida condiciona la estructura de aquellos ámbitos que Rawls considera no políticos o no públicos.

Una concepción política de la justicia tiene los siguientes rasgos característicos. En primer lugar, es una concepción moral de la estructura básica

42 Ibídem p. 40 y 229. En ésta última Rawls afirma que «hay que distinguir las virtudes políticas de las virtudes que definen modos y estilos de vida característicos de doctrinas comprehensivas religiosas y filosóficas, así como de las virtudes típicas de varios ideales asociativos (los ideales de iglesias y universidades, de empleos y vocaciones, de clubs y equipos) y de las que resultan adecuadas en el ámbito de la vida familiar y de las relaciones personales».

43 Ibídem pp. 255-257.

44 Ibídem p. 169. También se refiere a la naturaleza afectiva de los vínculos familiares en la p. 253.

45 Ibídem pp. 167-168.

46 Ibídem p. 261.

${ }^{47}$ Ibídem pp. 40, 45, 67, 128. 
de la sociedad ${ }^{48}$. No se trata de una concepción puramente formal o procedimental sino que su contenido viene dado por ciertos valores materiales. En la justicia como equidad algunos de esos valores importantes son los de «igual libertad política y civil; la igualdad equitativa de oportunidades; los valores de reciprocidad económica; las bases sociales del respeto mutuo entre ciudadanos ${ }^{49}$. Tampoco se trata de una mera teoría de la elección racional que base la posibilidad del consenso en intereses egoístas y en el resultado de una negociación. La concepción de la justicia que es el núcleo de un consenso entrecruzado se basa en razones morales, que incluyen concepciones de la sociedad -como sistema equitativo de cooperación socialy de los ciudadanos - como personas libres e iguales, dotadas de la capacidad para poseer un sentido de la justicia y para sostener una concepción del bien propia-, así como principios de justicia y una descripción de las virtudes políticas a través de las cuales aquellos principios se materializan en el carácter humano y se expresan en la vida pública ${ }^{50}$.

En segundo lugar, no se trata de una concepción de la justicia general o comprehensiva. Trata de elaborar una concepción razonable sólo para la estructura básica y, en la medida de lo posible, no implica compromisos con ninguna otra doctrina ni ideales para la vida humana en su globalidad ${ }^{51}$.

Por último, la concepción política de la justicia está expresada en ciertas ideas fundamentales que se entienden implícitas en la cultura política pública de una sociedad democrática. Esa cultura pública abarca las instituciones políticas de un régimen constitucional y las tradiciones públicas de su interpretación, así como los textos históricos que son de conocimiento común. Se diferencia del «trasfondo cultural» de la sociedad civil o cultura social que es la cultura de la vida cotidiana, de sus varias asociaciones. Rawls distingue, así, lo político de lo no político, que coincide con su distinción entre lo público y lo no público, concibiendo al primer ámbito como la esfera de las ideas y principios fundamentales implícitamente com$\operatorname{partidos}^{52}$.

\footnotetext{
${ }^{48}$ Ibídem p. 41.

${ }^{49}$ Ibídem p. 171.

50 Ibídem p. 179.

51 Ibídem pp. 42-43.

52 Ibídem pp. 38, 43-44. En resumen, cuando Rawls afirma que una concepción de la justicia es política quiere decir tres cosas: «que está armada de tal modo que sólo sirve para ser aplicada a la estructura básica de la sociedad -a sus instituciones políticas, sociales y económicas principales- como un esquema unificado de cooperación social; que se presenta de una manera independiente de cualquier doctrina religiosa o filosófica comprehensiva más amplia y abarcante; y que está elaborada en términos de ideas políticas fundamentales que se entienden implícitas en la cultura política pública de una sociedad democrática» (ibídem p. 258).
} 
Que la concepción política de la justicia sea independiente, como señalaba en el segundo rasgo característico, no implica que los valores políticos estén separados respecto del resto de valores ni que sea una concepción compatible con cualquier proyecto moral. Por lo que se refiere al primer aspecto, la aceptación por los ciudadanos de la concepción política no es un compromiso entre quienes sostienen doctrinas morales o filosóficas diferentes, sino que se basa en un conjunto de razones derivadas de la propia doctrina comprehensiva de cada ciudadano. El consenso de las distintas doctrinas consigue la adhesión mediante un ajuste concordante entre la concepción política y las exigencias de cada concepción del bien (la idea de «equilibrio reflexivo» $)^{53}$.

Por otra parte, los principios de cualquier concepción política, aunque no constituyan una doctrina moral general y comprehensiva, deben imponer restricciones a las doctrinas morales -esencialmente la restricción de que sean razonables ${ }^{54}-$, del mismo modo que las instituciones básicas recomendadas por aquellos principios alientan o desalientan determinados estilos de vida. Ello es así, al menos, por dos razones: los estilos de vida recomendados por las doctrinas comprehensivas pueden entrar en conflicto con los principios de justicia; o bien, aun siendo admisibles, pueden perder adeptos en las condiciones políticas y sociales de un régimen constitucional justo. Ejemplo del primer caso sería una doctrina moral que implicara la degradación de determinadas personas por motivos raciales, étnicos o perfeccionistas, como en el caso del esclavismo. Ejemplo del segundo serían determinadas formas de religión, como aquellas que sólo pueden sobrevivir si tienen el control estatal ${ }^{55}$.

\footnotetext{
53 Ibídem pp. 201-205.
}

${ }^{54}$ Vid. pp. 89-97 sobre las doctrinas comprehensivas razonables. Rawls define lo razonable del siguiente modo: «las personas son razonables en un aspecto básico cuando estando, digamos, entre iguales, se muestran dispuestas a proponer principios y criterios en calidad de términos equitativos de cooperación, y a aceptarlos de buena gana siempre que se les asegure que los demás harán lo mismo... Lo razonable es un elemento de la idea de sociedad como sistema de cooperación equitativa, y que los términos equitativos de ésta sean razonables para todos es parte de su noción de reciprocidad... Las personas razonables no están movidas por el bien general como tal, sino por el deseo mismo de un mundo social en el que ellas, como libres e iguales, puedan cooperar con las demás en términos que todo el mundo pueda aceptar» (ibídem pp. 80-81).

55 Ibídem pp. 223, 229-231, 245. J. Exdell considera que este aspecto de la doctrina de Rawls es contradictorio con su pretensión de legitimar el Estado liberal y buscar las bases de un consenso general. Por una parte, Rawls se esfuerza por distinguir lo personal de lo político, y el liberalismo político del liberalismo como doctrina moral comprehensiva. Pero, por otra parte, afirma que el liberalismo político impone restricciones a los modos de vida y justifica políticas estatales que favorecen ciertos valores morales. Difícilmente se lograría un consenso universal en torno a una constitución liberal si conlleva restricciones en los modos de vida que defienden ciertas doctrinas conservadoras o fundamentalistas (John EXDELL, «Feminism, 
Ello implica la «primacía de lo justo», es decir, que los principios de justicia de una concepción política ponen límites a los estilos permisibles de vida. «La primacía de lo justo otorga a los principios de justicia una prioridad estricta en las deliberaciones de los ciudadanos, y limita su libertad de adoptar ciertos estilos de vida. La primacía de lo justo es característica de la estructura y el contenido de la justicia como equidad y de lo que ésta considera buenas razones en el proceso de deliberación» ${ }^{56}$. La concepción política de la justicia nos indica qué cuestiones pueden eliminarse razonablemente de la agenda política y cuáles no pueden eliminarse. Decir que determinadas cuestiones pueden ser eliminadas de la agenda política quiere decir que no se consideran objeto de decisión política sujeta a la regla de la mayoría, porque las libertades básicas iguales que se refieren a esas cuestiones «se consideran razonablemente fijadas, correctamente sentadas de una vez por todas $»^{57}$. En este sentido, los principios de justicia referidos a esas cuestiones básicas garantizan una protección a los individuos y las asociaciones tanto frente al Estado como frente a otros individuos y asociaciones ${ }^{58}$.

S. M. Okin ha afirmado que es difícil reconciliar la tesis de Rawls acerca de que una sociedad política justa no permitiría la práctica de concepciones morales irrazonables con su pretensión de que la justicia como equidad es una teoría estrictamente política. «Parece que, aunque frecuentemente lo niega, él sostiene que las personas que viven en una sociedad justa deben ordenar la totalidad de sus vidas -no sólo sus aspectos políticosde conformidad con la justicia ${ }^{59}$. Creo, sin embargo, que Rawls matizaría

Fundamentalism, and Liberal Legitimacy», Canadian Journal of Philosophy, vol.24, n.3, 1994, pp.449-455).

56 J. RAWLS, El liberalismo político, op. cit., p. 244. También pp. 208-209.

${ }^{57}$ Ibídem p. 183. Rawls pone como ejemplo de asuntos no sujetos a la regla de las mayorías, por estar definitivamente resueltos a partir de los principios constitucionales de libertad de conciencia e igualdad de libertades políticas y civiles, las verdades religiosas, por una parte, y la servidumbre y la esclavitud, por otra. En un artículo anterior, que fue el germen de esta conferencia IV, Rawls es más explícito al señalar que estas cuestiones «son parte del fuero público de un régimen constitucional, y no un asunto apropiado para la legislación y discusión pública continuas, como si pudieran ser cambiadas en cualquier momento, en un sentido u otro» (John RAWLS, «La idea de un consenso por superposición», trad. de J.C.Bayón, en J. Betegón y J. R. de Páramo (coords.), Derecho y moral. Ensayos analíticos, Ariel, Barcelona, 1990, p. 75 n. 22).

${ }^{58}$ Rawls se refiere a la libertad de culto como protección del individuo frente a la iglesia, del mismo modo que la libertad de culto y otras libertades, como la libertad de asociación, protegen a las iglesias frente al Estado y otras asociaciones poderosas (J. RAWLS, El liberalismo político, op. cit., n. 8 p. 256).

${ }^{59}$ Susan Moller OKIN, recensión a J.Rawls «Political Liberalism» en American Political Science Review, vol. 87, n. 4, 1993, p. 1011. 
esta conclusión. La concepción política de la justicia no impone un contenido sustantivo a las concepciones comprehensivas del bien, sino que sólo las limita ${ }^{60}$. Cada individuo y cada asociación no política se rige por sus propios ideales y valores, de forma que los principios políticos de justicia no se aplican directamente a su vida interna. Sin embargo, tales principios imponen ciertas restricciones esenciales tanto a los individuos como a las asociaciones ${ }^{61}$.

Esta es la interpretación que Rawls ha expuesto en uno de sus escritos posteriores a El liberalismo político. «The Idea of Public Reason Revisi$t e d \gg^{62}$ es especialmente relevante para el tema que nos ocupa porque en él, por primera vez, el autor se refiere directamente a las cuestiones de familia y género en relación con su concepción de la justicia. Presenta la familia como una institución o asociación no política a la que, en consecuencia, no se aplican directamente los principios liberales de la justicia política. Sin embargo, que no sea una institución política o pública no implica que constituya una esfera ajena a las exigencias de la justicia. Los principios que definen la igualdad de libertades y oportunidades de todos los ciudadanos se aplican igualmente a los miembros de cualquier asociación o institución pública o no pública. Ello no obsta para que la vida doméstica pueda regirse por exigencias morales propias, como las relativas a cómo -dentro de ciertos límites- educar a los hijos. Pero, en todo caso, el liberalismo político no considera el ámbito político y el no político como espacios separados, desconectados, regido cada uno de ellos solamente por sus principios propios. «Las esferas de lo político y lo público, de lo no público y lo privado, caen bajo el contenido y aplicación de la concepción de la justicia y sus principios. Si se pretende que la denominada esfera privada sea un espacio exento de justicia, entonces no existe tal cosa» ${ }^{63}$.

Además, el liberalismo igualitario de Rawls reconoce la necesidad de las acciones políticas afirmativas, al asumir que los miembros de los grupos desfavorecidos pueden ver afectados sus derechos individuales. La igualdad plena de todos los ciudadanos exige medidas positivas que la favorezcan. Puesto que, en el caso de las mujeres, una de las causas principales de desigualdad es su mayor participación en el cuidado y educación de los hijos,

60 J. RAWLS, El liberalismo político, op. cit., p. 245.

${ }^{61}$ En relación con la familia, Rawls afirma que los derechos básicos que derivan de la concepción política de la justicia protegen a las familias frente al Estado y a otras asociaciones, así como a los miembros individuales de la familia frente a otros miembros (las mujeres frente a sus maridos, los hijos frente a sus padres). Ibídem n. 8 p. 256.

62 John RAWLS, «The Idea of Public Reason Revisited», op. cit., 1997, pp. 765-807. Se refiere a la familia en las pp. 787-794.

${ }^{63}$ Ibídem p. 791. 
deben adoptarse medidas para igualar el reparto de cargas o para compensar su mayor participación. En consecuencia, la concepción política de la justicia y los valores políticos que de ella derivan, se aplican a instituciones no políticas. Los valores políticos proporcionan «razones públicas» para todos los ciudadanos ${ }^{64}$.

\subsection{Lo público universal y la sociedad civil}

Frente a la «política de la diferencia» propuesta por una corriente crítica de la teoría política feminista, que subraya la relevancia de la heterogeneidad y la fragmentación moral y cultural en la construcción de lo público, Rawls insiste en la secularización de la vida pública y en la necesidad de distinguir lo político o público de la sociedad civil. Mientras que en el ámbito de lo público los individuos buscan un consenso acerca de una concepción política de «lo justo» que permita la realización de los fines sociales, en la sociedad civil los individuos persiguen sus propias concepciones del bien o sus planes de vida. ¿Quiere esto decir que las diferentes concepciones del bien no tienen cabida en el debate público?, ¿es incapaz la concepción rawlsiana de la política de dar cuenta del conflicto y las diferencias que caracterizan la práctica política ${ }^{65}$.

Rawls exige que en el foro público ${ }^{66}$ las cuestiones sean debatidas conforme al ideal de la razón pública siempre que impliquen consecuencias para los «fundamentos constitucionales» y las cuestiones de «justicia básica ${ }^{67}$. Ese ideal impone restricciones importantes al debate público, en cuanto que -como he señalado más arriba- exige presentar las pretensiones como justificables desde los requerimientos de generalidad y reciprocidad. Pero no supone la exclusión del debate de las concepciones del bien o los valores no políticos siempre que se aporten razones políticas en su defensa. La justificación pública de cualquier doctrina que se presente al debate público ha de basarse en premisas y alcanzar conclusiones que quepa razona-

\footnotetext{
${ }^{64}$ Ibídem pp. 792-794.

65 Esta es la crítica que ha dirigido a la teoría de Rawls Chantal MOUFFE en «Political Liberalism. Neutrality and the Political», en Ratio Iuris, vol. 7, n. 3, 1994. También en un sentido similar, J. EXDELL, «Feminism, Fundamentalism, and Liberal Legitimacy», op.cit., pp. 456-461. En lo que sigue, adopto, en parte, el planteamiento que de este tema hace Fernando VALLESPÍN en su Introducción a J. HABERMAS y J. RAWLS, Debate sobre el liberalismo político, op. cit., pp. 24-27.

66 J. RAWLS, El liberalismo político, op. cit., p. 250.

${ }^{67}$ Los fundamentos constitucionales definen la estructura general del Estado y el proceso político así como la igualdad de derechos y libertades básicos de los ciudadanos que han de respetar las mayorías legislativas. Los asuntos de justicia básica se refieren a cuestiones de justicia distributiva tales como la libertad de movimientos y la igualdad de oportunidades, las desigualdades sociales y económicas y las bases sociales del autorrespeto (ibídem pp. 249, 262-265).
} 
blemente esperar que sean aceptadas por otros. De este modo se satisface el deber de civilidad para con los demás ciudadanos. Mostrar una doctrina como aceptable para todos exige evidenciar cómo salvaguarda los valores constitucionales básicos y es conforme con una concepción política de la justicia razonable ${ }^{68}$.

La obligación de presentar razones políticas adecuadas para defender cualquier concepción del bien en el debate público es lo que caracteriza la cultura política pública frente al trasfondo cultural de la sociedad civil ${ }^{69}$. Pero al margen de los principios propios de esa cultura política pública, relativos a las cuestiones constitucionales fundamentales, los ciudadanos pueden intervenir en temas políticos desde su concepción del bien particular. Como ha señalado Vallespín, «el requerimiento de la neutralidad y la razonabilidad no se extiende al resto de las cuestiones que son susceptibles de ser debatidas y decididas en cualquier democracia moderna» ${ }^{70}$. Las doctrinas comprehensivas de todo tipo forman la cultura social, la cultura de la vida cotidiana de las diversas asociaciones (iglesias, universidades, sociedades eruditas y científicas, clubes y equipos, etc. $)^{71}$. En esa cultura de la sociedad civil se explican y debaten toda suerte de doctrinas comprehensivas y se argumenta acerca de ellas sin la exigencia imperativa de la razonabilidad. Rawls equipara esta discusión no política que se desarrolla indefinidamente en la sociedad civil a la situación discursiva ideal de Habermas y la considera, más que un diálogo, un «omnílogo» ${ }^{72}$.

Por consiguiente, el aspecto deliberativo de la democracia y la discusión no excluyente se desarrolla en la teoría de Rawls en el seno de la sociedad

68 Vid. ibídem pp. 275-288 y J. RAWLS, «The Idea of Public Reason Revisited», op. cit., pp. 783-787. Uno de los ejemplos que cita Rawls es el de la discutida cuestión de la subvención estatal de las escuelas religiosas. Quienes defienden la subvención estatal exclusivamente de las escuelas públicas dudarán de que los grupos religiosos que defienden la primera acepten realmente los valores políticos fundamentales -en concreto, la igualdad de oportunidades y la separación iglesia/Estado-. Sería deseable que los líderes de los grupos en disputa presentaran en el foro público, no ya las raíces religiosas o éticas en que fundan sus posiciones, sino la manera en que creen que sus respectivas concepciones del bien afirman los valores políticos (El liberalismo político, p. 284, y «The Idea of Public Reason Revisited», p. 785). Tampoco la cuestión del aborto, por ejemplo, puede ser discutida públicamente a partir de las razones derivadas de una doctrina moral o religiosa particular, sino en los términos de los valores políticos implicados (respeto a la vida humana, reproducción ordenada de la sociedad política a lo largo del tiempo e igualdad de las mujeres). El liberalismo político, n. 32 pp. 278-9.

69 J. RAWLS, «The Idea of Public Reason Revisited», op. cit., p. 784.

${ }^{70}$ F. VALLESPÍN, Introducción a J. HABERMAS y J. RAWLS, Debate sobre el liberalismo político, op. cit., pp. 25-26.

71 J. RAWLS, El liberalismo político, op. cit., p. 44.

72 J. RAWLS, «Réplica a Habermas» en J. HABERMAS y J. RAWLS, Debate sobre el liberalismo político, op. cit., pp. 86-89. 
civil, mientras que el debate público o político se limita a definir la estructura constitucional y la justicia distributiva básicas aceptadas por todos como condición general para la libre discusión social. Las deliberaciones colectivas acerca de las posiciones o doctrinas de los distintos grupos e individuos se pueden desarrollar en los diversos espacios sociales y asociaciones que existen al margen del Estado. En consecuencia, Rawls no subordina el bien de la sociedad civil al de la vida pública y sostiene, por el contrario, que la democracia política depende de un trasfondo cultural liberal que la sostiene ${ }^{73}$. La concepción alternativa de lo político que propone un sector del feminismo, desde autoras como Young o Benhabib, como heterogéneo y no excluyente se traslada en el liberalismo de Rawls a la sociedad civil $^{74}$, por lo que en su teoría se perpetúa la distinción liberal entre el ámbito público universal de la ciudadanía y un espacio privado de identidades, intereses y roles particulares ${ }^{75}$.

El problema radica en que el intento de conciliar esa ciudadanía más participativa con el respeto de ciertas normas constitucionales básicas lleva en la teoría de Rawls a una limitación de los resultados deliberativos. Habermas ha criticado el modelo político de Rawls al considerar que el establecimiento de los principios de justicia en la posición original somete la participación democrática de la ciudadanía a un modelo teórico en cuya elaboración ella no ha intervenido. Puesto que los ciudadanos como tales no participan en la posición original, es el filósofo el que desarrolla la idea de una sociedad justa de modo pre-político. «Cuanto más se levanta el velo de

${ }^{73}$ Ibídem pp. 127-128.

${ }^{74}$ Elena Beltrán ha señalado que la discusión acerca del papel del Estado y de la sociedad civil está en el fondo de las críticas que las autoras como Pateman, Benhabib y Mouffe hacen al liberalismo, y es también la cuestión que se plantean los liberales como Rawls o Kymlicka (E. BELTRÁN, «Público y privado. Sobre feministas y liberales: argumentos en un debate acerca de los límites de lo político», Doxa, 15-16, 1994, pp. 404-405).

75 Además estas autoras discrepan del modo en que Rawls da cuenta del pluralismo de las sociedades contemporáneas. I. M. Young, aunque reconoce que la noción de «consenso por superposición» de Rawls supone un avance en la atención a la diferencia y el pluralismo, estima que la idea de doctrina comprehensiva en la que descansa ese acuerdo político no es adecuada. En primer lugar, considera que es una idea demasiado estrecha para captar la realidad de las sociedades multiculturales, en las que las prácticas, la cultura, las creencias, etc., que definen y motivan un modo de vida no constituyen un cuerpo doctrinal sistemático y comprehensivo. En segundo lugar, es una idea demasiado totalizante, puesto que los individuos en las modernas sociedades plurales no regulan la totalidad de su vida por un cuerpo único de creencias. La idea de una doctrina comprehensiva nos hace concebir erróneamente el pluralismo social como el enfrentamiento entre grupos coherentes y uniformes con valores comunes claramente identificables, cuando en realidad el moderno pluralismo social es más complejo y fluido (I. M. YOUNG, «Rawls`s Political Liberalism», The Journal of Political Philosophy, vol.3, n.2, 1995, pp.182-186). 
ignorancia y más adoptan una forma real de carne y hueso, los ciudadanos de Rawls se encuentran más profundamente inmersos en la jerarquía de un orden progresivamente institucionalizado por encima de sus cabezas. Así la teoría sustrae a los ciudadanos buena parte de aquellas intuiciones que cada generación tendría que hacer suyas de nuevo». La rígida frontera entre la identidad política y la identidad no pública de los ciudadanos «viene trazada por los derechos liberales básicos que limitan la autolegislación democrática y con ello la esfera de lo político de entrada, es decir, con anterioridad a toda formación política de la voluntad» ${ }^{76}$.

Rawls no considera, sin embargo, que las cuestiones constitucionales básicas estén especificadas con anterioridad a la deliberación democrática. La estructura básica de las instituciones políticas no es obra de la filosofía política sino que se basa en la concepción política de la justicia que está sometida a lo largo del tiempo a los juicios reflexivos de la sociedad civil. La posición original es sólo una idea abstracta mediante la que imaginamos qué principios elegirían imparcialmente las partes, pero no es más que una de las cuatro etapas en la que se despliega la idea de justicia como equidad: posición original, convención constitucional, legislación e interpretación ${ }^{77}$. Los ciudadanos discuten continuamente los principios políticos a lo largo de todas las etapas, puesto que el ideal de una constitución justa se elabora progresivamente en el tiempo. Rawls afirma que «desde el punto de vista de los ciudadanos en el trasfondo cultural... en la etapa de la convención constitucional, tras haber elegido los principios de la justicia en la posición originaria, adoptamos una Constitución que, con su carta de derechos y otras disposiciones, restringe la legislación de la mayoría... De esta manera restringe la soberanía popular expresada en la legislación». Pero «estas libertades básicas no se encuentran en un dominio prepolítico»; la justicia como equidad «permite -pero no exige- que las libertades básicas se hallen incorporadas en la Constitución y sean protegidas como derechos constitucionales sobre la base de las deliberaciones y juicios de los ciudadanos a lo largo del tiempo» ${ }^{78}$.

Sin embargo, como señala Vallespín, los ciudadanos sólo participan en el debate público plenamente conscientes de su propia identidad y de sus intereses respectivos una vez que los principios de la razón pública han sido objetivados en la teoría y en la Constitución. «El espacio público no sirve, pues, para generar, redefinir o encontrar intersubjetivamente dichos princi-

76 Jürgen HABERMAS, «Reconciliación mediante el uso público de la razón», en J.Habermas y J.Rawls, Debate sobre el liberalismo político, op. cit., pp. 66-67.

77 J. RAWLS, «Réplica a Habermas», op. cit., pp. 102-105.

78 Ibídem pp. 110-111. 
pios a través del debate, sino únicamente para constreñir la forma en la que se han de presentar los argumentos en defensa de intereses e ideas pre-definidos, y conseguir el apoyo más extenso posible para los mismos. Este es el punto en el que se separa decisivamente de una teoría de la democracia deliberativa a lo Habermas» ${ }^{79}$.

Tanto Rawls como Habermas coinciden, ante al actual pluralismo cultural y de formas de vida, en la búsqueda de un ámbito de argumentación pública en el que todos se orienten hacia un consenso respecto de la justicia de las normas que hayan de afectarles ${ }^{80}$. Es decir, ambos reconocen la necesidad de que el sistema jurídico-político proteja aquellos derechos básicos que permitan a cada individuo o grupo desarrollar sus propios planes de vida. Pero, al mismo tiempo, abren la esfera pública a las reivindicaciones de los individuos y grupos y reconocen la necesidad de acciones políticas afirmativas a favor de sus identidades o intereses. La diferencia de la teoría de Rawls se encuentra en las restricciones teóricas que impone a ese debate público.

A pesar de que en ocasiones se ha entendido que la posición original de Rawls puede implicar la necesidad de adoptar el punto de vista del otro ${ }^{81}$, las condiciones del velo de ignorancia lo presentan haciendo abstracción de su identidad concreta, de las necesidades y deseos, intenciones y atributos, propósitos y fines que caracterizan a los individuos en su particularidad ${ }^{82}$. Para S.Benhabib en la posición original no existe una verdadera pluralidad de perspectivas sino únicamente una identidad definicional ${ }^{83}$. En este sentido, la concepción de Rawls trataría de ser coherente con el concepto kantiano de autonomía moral y, como éste, sería un modelo «monológico» de razonamiento moral.

Aunque la posición original constituye exclusivamente la primera etapa en la secuencia que conduce al establecimiento de una concepción política de la justicia, va a condicionar la reflexión constitucional -y posteriormente la legislativa y la interpretativa- de los principios básicos. Es cierto que la posición original es sólo una conjetura que debe ser examinada. En pala-

\footnotetext{
${ }^{79}$ F. VALLESPÍN, Introducción a J. HABERMAS y J. RAWLS, Debate sobre el liberalismo político, op. cit., p. 28.

${ }^{80}$ Ibídem pp.36-37.

${ }^{81}$ Okin ha considerado las nociones de «posición original» y «velo de la ignorancia» como herramientas epistémicas adecuadas para que cada individuo comprenda el punto de vista de los demás. Para esta autora, la posición original exige una fuerte empatía y una tendencia a escuchar los diferentes puntos de vista de los demás (S. M. OKIN, Justice, Gender and the Family, op. cit., p. 101).

82 Michael SANDEL, El liberalismo y los límites de la justicia, Gedisa, Barcelona, 2000.

${ }^{83}$ S. BENHABIB, «El otro generalizado y el otro concreto», op. cit., pp. 137-143.
} 
bras de Rawls, «somos tú y yo y todos los ciudadanos en el tiempo, uno por uno y en asociaciones aquí y allí, quienes juzgamos los méritos de la posición original como un mecanismo de representación y los principios que le subyacen ${ }^{84}$. Habrá que ver en qué medida esos principios se aplican a las instituciones democráticas y cuáles serían sus resultados, y en consecuencia en qué medida encajan en la práctica con nuestras concepciones ponderándolas con la debida reflexión ${ }^{85}$. Pero los principios que derivan de la posición original condicionan ya el debate público, con el fin de garantizar su imparcialidad y razonabilidad. La concepción de la democracia de Rawls no logra evitar la crítica de paternalismo filosófico y, con ella, de concepción monológica ${ }^{86}$.

84 J. RAWLS, «Réplica a Habermas», op. cit., p. 87 n. 15.

85 Ibídem pp. 84-85.

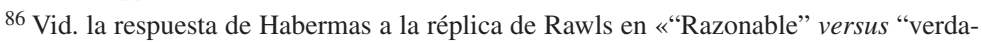
dero", o la moral de las concepciones del mundo», en J. Habermas y J. Rawls, Debate sobre el liberalismo político, op. cit., pp. 147-181. 
$\triangle \quad$ DOXA 24 (2001) 